Letícia Gonzaga Chacon*

Universidade Federal de Goiás

Priscila Renata Gimenez**

Universidade Federal de Goiás

\title{
As 'Vanguardas Futuristas' Brasileiras: O Embate Literário nos Periódicos dos Anos de 1920
}

Resumo:

O presente artigo tem como objetivo o estudo da relação que se estabeleceu no Brasil entre os periódicos do início do século XX e o Movimento Modernista. A finalidade do trabalho é demonstrar como a imprensa periódica, enquanto suporte democrático e espaço público, contribuiu para a propagação do movimento e para o seu estabelecimento no cenário cultural brasileiro. A hipótese norteadora do trabalho consiste em afirmar que o caráter polêmico e conflituoso das notícias que circulavam na imprensa, antes mesmo da realização da Semana de Arte Moderna (1922), deve ser considerado como um instrumento da divulgação do movimento. Para tanto, serão analisados os conteúdos de notícias e críticas literárias de diferentes periódicos que antecedem o acontecimento da Semana de Arte Moderna, enfatizando a relação que se estabeleceu entre as publicações e suas respectivas reverberações sobre o Modernismo brasileiro.

Palavras-chave:

arte moderna, Movimento Modernista, periódicos

\section{Abstract:}

This article aims to study the relationship established between the magazines of the early 2oth century and the Brazilian Modernist Movement. The objective of the work is to demonstrate how the newspaper, as a democratic vehicle and public space, contributed to the spread of the movement and its subsequent edification the Brazilian cultural scene. The guiding hypothesis of the work is to state that the controversial and conflicting aspect of the news that circulated in the press, even before the conclusion of the Modern Art Week, should be considered as an instrument of this propagation. To this end, the contents of certain news and literary criticisms from different periodicals, which preced the event of the Week Modern Art, will be analyzed, emphasizing in the discussion the relationship established between the publications and their respective responses.

\section{Keywords:}

modern art, modernist movement, periodicals. 


\section{Introdução}

O Modernismo Brasileiro, enquanto movimento ideológico e cultural, recebeu uma série de refutações, réplicas e argumentações; gerou discussões intensas, proporcionou boas recepções e, também, muitas objeções às variadas concepções estéticas que estruturaram a sua base. Inúmeros jornais e revistas, enquanto espaços públicos, proporcionaram debates de variadas naturezas. Dentro deste contexto, a Semana de Arte Moderna, realizada na cidade de São Paulo, no Teatro Municipal, entre os dias 11 e 18 de fevereiro de 1922, se caracteriza como um marco político e cultural deste movimento que, posteriormente, se consolidou no cenário cultural brasileiro.

Próximo do seu centenário, a realização do evento ainda suscita questionamentos até os dias de hoje: o Movimento Modernista só se constituiu enquanto tal por consequência da Semana? o evento era homogêneo, apresentando todos os seus organizadores e participantes um mesmo ideal e objetivo?

Após inúmeros estudos sobre o tema, podemos trazer à tona algumas informações: nos últimos anos, muitos têm apontado a natureza das abundantes polêmicas que cercaram a Semana de Arte Moderna e muito se sabe sobre a divisão artística que resultou destes conflitos: as várias vertentes estéticas do movimento que surgia, orientaram diferentes tipos de conduta e posicionamentos dos seus participantes durante a Semana de 22. A realização do evento apresentou inúmeras falhas em sua organização, desde problemas de natureza financeira até mesmo à ocorrência de divergências pessoais entre os principais artistas e intelectuais realizadores do evento (Tércio 2019).

De fato, é conhecido e revisto por especialistas a conjuntura de que não se tratava de um evento homogêneo. Todavia, não se pode afirmar que os artistas organizadores deste festival não tinham em comum um objetivo; isso seria demolir e desfigurar toda a construção de um caminho já traçado há quase cem anos. Mesmo considerando o fato de que a maior parte das polêmicas se referiam principalmente à divergência de concepções estéticas entre os próprios organizadores, não se deve considerar todo o evento um conflito em si mesmo.

A origem das confusões que se estabeleceram entre os intelectuais - e algumas das reações hostis por parte do público mediante as apresentações artísticas realizadas durante o evento -, não foram consequências da própria Semana. Muito se deve considerar o papel de todos os veículos midiáticos e informativos da época na construção de uma imagem do movimento que surgia. Antes mesmo da realização do festival, o grupo de intelectuais e artistas, organizadores da Semana de 22, era alvo de duras críticas e enfrentamentos de natureza intransigente por determinada classe de artistas opositores ao evento, e também por parte da sociedade paulistana. Grande parte desses enfrentamentos ocorreu em função da importação de ideias e concepções estéticas modernas no Brasil no início do século XX.

Os responsáveis pela incorporação dessas ideias modernas, dentro do contexto artístico e social brasileiro, se envolveram em legítimos debates na defesa da realização dessa nova arte. Debates que, tendo a imprensa brasileira como palco principal, conduziram toda a discussão sobre o Movimento Modernista a outro nível de argumentação: o caráter intelectual e formal 
das conferências sobre arte transfigurou-se, adquirindo uma caracterização informal e intriguista.

Tendo em vista tais contexto e acontecimentos, este estudo pretende mostrar a relação que se consolidou no Brasil entre os periódicos do início do século XX e o Movimento Modernista no período que antecedeu a Semana de 22 , enfatizando a relação que se estabeleceu entre as publicações e suas respectivas reverberações sobre o Modernismo brasileiro, tanto por parte do público - leitor/espectador - quanto dos artistas. A imprensa periódica, enquanto suporte democrático e espaço público, contribuiu para a divulgação do movimento e para a sua consolidação no cenário cultural brasileiro sendo veículo e suporte de notícias, artigos de opinião e, naturalmente, de polêmicas que circularam nos jornais antes da realização da Semana de Arte Moderna (1922), o que certamente projetou holofotes na aurora do movimento.

\section{Polêmicas, Imprensa e Modernismo: antes da semana de 22}

Bem sabemos que o Modernismo, enquanto escola literária, não se reduziu somente a um direcionamento estético: várias foram as concepções estéticas que sustentaram a sua base e vários foram também os grupos nos quais se subdividiu - as denominadas vanguardas europeias, os conhecidos movimentos do Futurismo, Expressionismo, Cubismo, Dadaísmo e Surrealismo, que estabeleceram a essência da escola modernista. Contudo, a divisão de grupos estéticos, que deveria ocorrer de forma natural e pacífica, considerando a essência total e plural do movimento, foi realizada de forma não harmoniosa dentro do contexto social brasileiro.

Em se tratando dessas diversas concepções, uma em específico se tornou o alvo de discussão e polêmica da imprensa brasileira: a corrente estética do Movimento Futurista, fundado por Filippo Tommaso Marinetti (1876-1944) em 1909, foi hostilizada por colaboradores de jornais e revistas nacionais desde sua primeira menção no jornal Correio da Manhã, no mesmo ano de publicação do manifesto. ${ }^{1}$ Como se verá adiante, o mais conhecido grupo de poetas modernos brasileiros foi o principal alvo de tais hostilizações.

Os debates mais efervescentes, então, foram direcionados ao campo da poesia, a partir do ano de 1921, quando, de acordo com Mário da Silva Brito (1997), ocorreu a publicação dos primeiros supostos versos futuristas na imprensa brasileira. ${ }^{2}$ Dado o fato de que o Classicismo, o Romantismo, o Parnasianismo e o Simbolismo figuravam ainda como as tradições poéticas que sustentavam a literatura brasileira naquele momento, as reações de grande parte dos intelectuais considerados "passadistas"3 ${ }^{3}$ pelos líderes pioneiros do Movimento Modernista, não foram receptivas.

É importante salientar que, mesmo sendo o grupo de poetas modernistas o alvo das principais acusações, as intrigas não se limitavam à escrita literária e tão somente à poesia. É conhecido o fato de que foi em torno da poesia, como mencionado acima, que se deu os maiores debates do movimento, e foi em torno dela que se precisou "o conflito entre o novo e o velho, o antigo e o moderno" (Nunes 2002: 39). A evolução e a essência do movimento se constituíram em torno da poesia, pois foi por ela que passou 
a principal linha divisória entre as exigências de renovação - a primeira das quais a maior liberdade do uso literário da língua - e o status quo parnasiano e naturalista para a literatura e acadêmico para as artes plásticas. Até 1925, salvo a exceção de Memórias Sentimentais de João Miramar, de Oswald de Andrade, o maior impacto do Modernismo veio do campo da poesia, tema predileto de debates, e termômetro das aspirações literárias e artísticas do movimento. (idem: 39, grifos nossos)

Porém, como já mencionado, a discussão em torno da poesia moderna só ganhou verdadeira força na imprensa brasileira a partir do ano de 1921. Contudo, alguns dos intelectuais adeptos da nova arte já realizavam algumas discussões sobre ideias e concepções de arte moderna na imprensa brasileira em um período anterior. É o caso de Oswald de Andrade, um dos principais fundadores do Movimento Modernista brasileiro, que em 1915 já publicava na imprensa brasileira crítica sobre arte moderna no âmbito das artes plásticas. O poeta, conhecido como o importador do futurismo brasileiro, ${ }^{4}$ publicou em 0 Pirralho, revista literária que fundou em 1911, o artigo "Em prol de uma pintura nacional", no qual defendia a busca de um nacionalismo moderno nas artes plásticas. Segundo Mário da Silva Brito (1997), tanto o conteúdo do artigo quanto a viagem realizada por Oswald três anos antes, eram um prenúncio "do que inventaria o movimento 'Pau-Brasil' - produto da cultura europeia e nacional" (Brito 1997: 30).

No que diz respeito à efervescência e explosão do movimento, segundo Gênese Andrade (2013), houve um evidente descompasso entre a apreensão de novas concepções estéticas na literatura e em outros âmbitos artísticos. De acordo com a autora, com exceção dos poemas de Paulicéia Desvairada, de Mário de Andrade, publicado em 1922, e "Os sapos", de Manuel Bandeira - declamado por Ronald de Carvalho, durante o acontecimento da Semana -, as obras literárias apresentadas até então "estavam longe de ser os textos emblemáticos da revolução modernista" (Andrade 2013: 128), visto que na esfera das artes plásticas, vários dos trabalhos importantes já haviam sido apresentados antes mesmo de 1922 - como a exposição da artista plástica Anita Malfatti, em 12 de dezembro de 1917, e a de Di Cavalcanti em 1921, na livraria e editora "O Livro" (Brito 1997).

Assim, o período anterior à década de 1920 apresentou a consolidação do debate sobre arte moderna, no que dizia respeito às artes plásticas, devido às contribuições críticas de Oswald de Andrade. Quanto à literatura, as discussões só tomaram certa efervescência pública após o aparecimento do artigo de Monteiro Lobato sobre a exposição de Anita Malfatti. O artigo intitulado "A propósito da exposição Malfatti" (mais conhecido como "Paranóia ou mistificação?"), publicado no jornal 0 Estado de S. Paulo, na edição de 20 de dezembro de 1917 é, talvez, a polêmica mais conhecida, dentre os estudos sobre o movimento modernista que antecede a realização da Semana de Arte Moderna. Muitos estudiosos o consideram o marco da difusão do início do movimento. A repercussão da opinião pública de um dos mais renomados escritores da literatura brasileira naquele dado momento, fez com que não somente o restante da imprensa voltasse os olhos para o Movimento Modernista enquanto surgia, mas também, e acima de tudo, contribuiu para que determinadas concepções inflexíveis em relação ao movimento 
iniciante se estabelecessem em meio à sociedade da época e, sobretudo, no contexto social paulistano - que era naquele momento, o centro urbano mais desenvolvido do país: local de grande concentração demográfica, apresentava no início do século inúmeros avanços econômicos, industriais e culturais, e, nas palavras do poeta Mário de Andrade, era "fruto necessário da economia do café e do industrialismo consequente" (Andrade 1942: 236).

O texto de Lobato elogiava o talento de Malfatti, apresentando concomitantemente ao elogio uma severa crítica às possíveis influências às quais a artista estava submetida. O escritor afirmou que a pintora possuía um "talento vigoroso, fora do comum", mas que infelizmente, estava seduzida pelas teorias do que denominava "arte moderna", pois "penetrou nos domínios dum impressionismo discutibilíssimo, e põe todo o seu talento a serviço duma nova espécie de caricatura" (Lobato 1917).

Se o artigo de Lobato fez com que grande parte da sociedade começasse a se preocupar com a arte que estava sendo produzida no país, o preconceito que sustentava parte de seu argumento não era, então, novidade na imprensa. As ideias modernas sobre arte eram vistas como simples agitações políticas, causadoras do caos e ameaça à vida cultural arcaica brasileira, estabelecida ainda em ideais estéticos assentados nas tradicionais correntes artísticas do século XIX. O movimento futurista, especificamente, era reconhecido como um movimento marginal, desrespeitoso às tradições do país, e seus admiradores eram vistos como possíveis transgressores da "verdadeira arte".

Segundo Annateresa Fabris (2011), uma das críticas mais conflituosa em relação ao Movimento Futurista foi realizada por José Veríssimo (1857-1916), escritor, crítico e jornalista brasileiro. $\mathrm{O}$ artigo intitulado "Mais uma extravagância literária" foi publicado no jornal 0 Imparcial, na edição do dia 05 de setembro de 1913. O artigo trazia em seu conteúdo, de acordo com Annateresa Fabris, uma crítica severa ao movimento futurista, comparando-o a um tipo de "anarquia mental", "procura doentia" e "extravagante" (apud Fabris 2011: 3). Até anos depois da publicação do artigo, as argumentações de Veríssimo eram retomadas em alguns escritos pelos intelectuais modernistas com certo tom de zombaria e deboche (Brito 1997). Contudo, da mesma forma que no artigo de Manoel de Sousa Pinto no Correio da Manhã, a crítica se dirigia ao movimento enquanto acontecia na Europa e não no Brasil, visto que, antes de 1913, apenas Oswald de Andrade se configurava como o importador das boas novas do futurismo italiano no contexto social brasileiro enquanto poeta, pela criação do poema "Último passeio de um tuberculoso pela cidade", de 1912.

Entretanto, deve-se considerar que as críticas, mesmo que dirigidas ao movimento enquanto acontecia na Europa, auxiliaram na distorção da imagem do Futurismo e, consequentemente, das ideias de arte moderna no solo brasileiro. Isso se deve à natureza de protesto e combate do conteúdo das notícias publicadas: antes mesmo da publicação polêmica do artigo de Lobato, o jornal A Gazeta, edição de São Paulo, havia publicado em 03 de março de 1916, uma nota anônima intitulada "O futurismo". A nota trazia em seu conteúdo uma crítica ferrenha à difusão do movimento entre os poetas italianos do início do século XX. ${ }^{5}$ Segue abaixo um trecho da nota: 
Entre os poetas está assumindo proporções simplesmente impossíveis. E não há quem se levante contra esses innovadores que apregoam de boca cheia as maravilhas de seus nobres e altos ideaes! Os latinos são os principaes responsaveis por essa revolução que se vai operando com uma rapidez extraordinaria, até empolgar os espiritos. É na Italia que, actualmente, os poetas futuristas arriscam as concepções mais arriscadas. Vamos aqui citar aos leitores da "Gazeta" uma série de exemplos do que a que se têm atrevido os versejadores da língua de Dante e de Petrarca. (O FUTURISMO 1916: 1)

Abaixo, segue a imagem da página da Gazeta em que a nota em questão foi publicada nas terceira e quarta colunas:

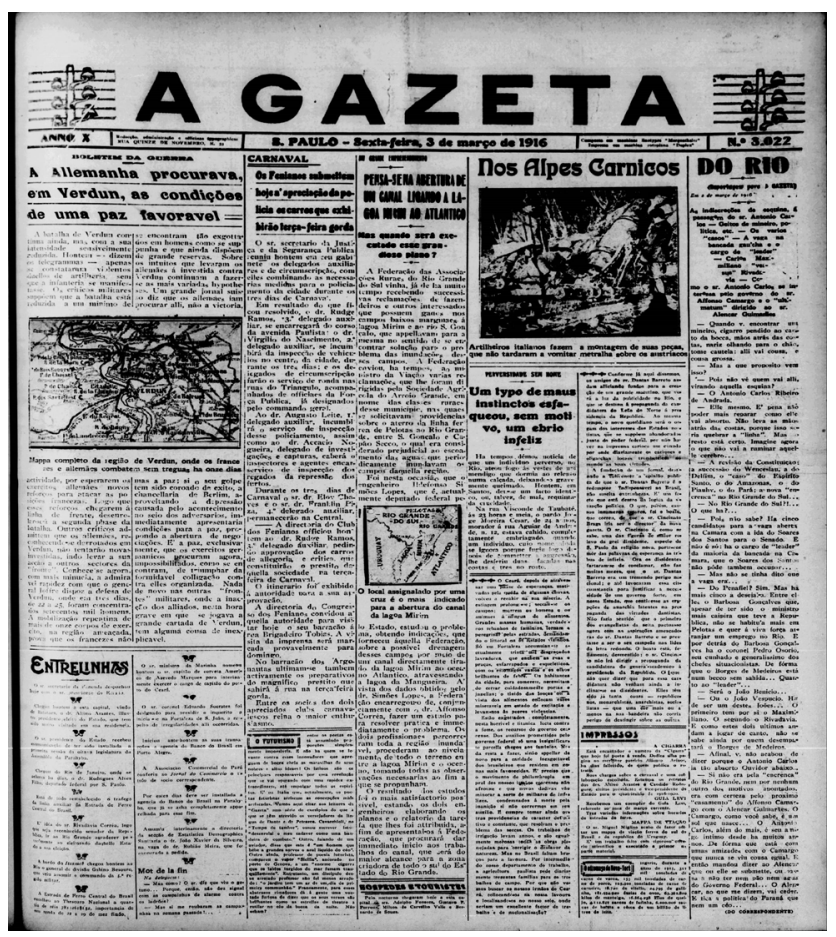

Figura 1 - A Gazeta, 03 de março de 1916, "O futurismo", p. 1

Fonte: Hemeroteca Digital Brasileira.

Em 1922, essas polêmicas e controvérsias ganharam proporções ainda maiores e se instauraram de vez no cenário cultural brasileiro. A redução e atribuição por grande parte da imprensa da designação de "futurismo" a um movimento tão amplo e plural como foi o Modernismo Brasileiro, provocou nos novos intelectuais uma indignação imensa, e a redarguição a esse apelido foi tão ampla quanto o próprio movimento em si. Dessa forma, criaram-se verdadeiros debates em torno das ideias sobre arte moderna. Havia, naquele momento, dois lados para se 
assumir um posicionamento estável: o lado favorável à realização de uma arte moderna brasileira, e o lado que não admitia a importação de ideias estrangeiras e consequente rejeição do modernismo como se desenvolvia no Brasil.

Essa designação genérica referente ao Modernismo Brasileiro e pejorativa referente ao Futurismo - ou melhor dizendo, a confusão que se deu entre os dois termos, transformando- os em verdadeiros sinônimos - se instituiu na imprensa brasileira após a publicação do artigo de Oswald de Andrade no Jornal do Commercio, na edição de 27 de maio 1921 . O artigo intitulado "O meu poeta futurista", explorado por Brito (1997) em seu trabalho de reunião dos grandes acontecimentos antecedentes à realização da Semana de 22, lançava pela primeira vez na imprensa brasileira Mário de Andrade enquanto poeta, e a estética inusitada do livro de poemas Paulicéia Desvairada (1922) - que até então, não havia sido publicado integralmente.

As controvérsias em torno do escrito decorreram não só da publicação dos versos de Mário - que até aquele momento eram inéditos; mas também, foram consequências das considerações peremptórias de Oswald acerca do movimento que se iniciava. Ele afirmava a existência de um suposto futurismo paulista. No texto, Oswald nomeava Mário como "poeta futurista", relacionando os versos da Paulicéia Desvairada diretamente à estética do futurismo de Marinetti. Oswald definiu o livro, ainda não publicado, como as "cinquenta páginas talvez da mais rica, da mais inédita, da mais bela poesia citadina" (apud Brito 1997: 226). ${ }^{6}$ O escritor não só afirmava como também exaltava o suposto Movimento Futurista no cenário cultural brasileiro: "Bendito esse futurismo paulista, que surge companheiro de jornada dos que aqui gastam os nervos e o coração na luta brutal, na luta americana, bandeirantemente!" (idem: 227).

De acordo com Brito (1997), o artigo de Oswald envolveu Mário de Andrade em verdadeiro escândalo na época. Segundo Goes, citado por Brito, o poeta - que naquele tempo era professor de música no Conservatório Dramático e Musical de São Paulo - , havia vivido sua vida pessoal, até então, de maneira harmoniosa. A partir do momento da publicação do artigo de Oswald, Mário passou "a ser apontado nas ruas, aos cochichos, sob olhares irônicos e sorrisos de mofa" (idem: 228).

O texto de Oswald, escrito em tom de manifesto, apresentava um protesto contra o que seria um pensamento provinciano e antiquado - a crítica às estruturas literárias passadas foi uma das bases de discussão do Movimento Modernista, tanto que, vinte anos após o acontecimento da Semana, Mário de Andrade afirmaria que o Movimento Modernista foi realizado por meio de um "espírito destruidor" (Andrade 1942). O manifesto de Oswald, então, gerou uma grande controvérsia entre os próprios artistas e intelectuais modernistas. Mário de Andrade vítima do mal-entendido - escreveria no mesmo jornal, dez dias depois, uma redarguição à alcunha de "futurista": "Não, o nosso poeta não se liga ao futurismo internacional, como não se prende a escola alguma" (Andrade 1921).

Essas discordâncias geradas no âmbito da imprensa, entre os próprios artistas e intelectuais do movimento, podem ser caracterizadas como os acontecimentos que fizeram do ano de 1921 "o ano fermento da Semana de Arte Moderna" (Brito 1997: 250). Não somente da Semana, o ano de 1921 seria o fermento das discussões que tomariam conta dos veículos midiáticos a 
partir do ano de 1922, também pós-realização da Semana de Arte Moderna - visto que as discussões e polêmicas sobre a nova estética, e as confusões entre o que seria arte moderna e arte propriamente futurista, se prolongaram para além desse período.

\section{"Arte Moderna” X “Arte Futurista": o periódico como espaço do embate literário}

Segundo Annateresa Fabris (2011), essa recepção negativa das ideias futuristas no Brasil ocorreu desde as primeiras menções à corrente literária. De acordo com a autora, o movimento foi fortemente "associado a manifestações patológicas e à agitação política, uma vez que suas propostas iconoclastas se chocavam com as poéticas realistas que dominavam o ambiente cultural brasileiro" naquele momento (Fabris 2011: 1). A figuração de uma ideia preconceituosa sobre o Futurismo, portanto, não era consequência imediata da circulação de notícias na imprensa ou da simples discussão estética recorrente no país. Segundo Angela Thalassa, apesar de todo o desenvolvimento urbano, industrial, econômico e moderno do centro paulistano no início do século vinte, a sociedade paulistana mantinha-se em uma nítida contradição: "apesar do dinamismo urbano de São Paulo, alavanca do país", a sociedade paulista ainda estava firmada em "elementos patriarcais e conservadores ligados ao mundo agrário e a intelectualidade recém-formada" (Thalassa 2007: 93).

Sendo assim, em se tratando do estabelecimento de uma nova escola literária, inovadora e marginal, crítica e transgressora, visto que se tratava de uma atividade de ruptura com um passado muito bem determinado, a imprensa brasileira e, especificamente a paulistana, contribuiu para reforçar, consolidar, e até mesmo refletir preconceitos muito antigos já enraizados no meio social brasileiro.

Dessa forma, deve-se considerar a importância do jornal na difusão do movimento: a circulação das discussões sobre as variadas correntes estéticas modernas só foi possível graças ao caráter democrático dos jornais, ${ }^{7}$ que correspondiam à própria ideia de modernidade. Assim sendo, em se tratando do Movimento Modernista, os periódicos assumiram força crucial nesse contexto artístico-cultural brasileiro. A abertura comunicativa, a possibilidade de se construir rapidamente uma réplica a conteúdos já publicados, orientou a profundidade das discussões críticas e teóricas acerca do que seriam, naquele momento, as bases do Modernismo Brasileiro enquanto potencial tradição literária.

Já mencionado anteriormente, o jornal A Gazeta, de São Paulo, pode ser considerado um dos veículos comunicativos que mais contribuiu para a construção de uma imagem conflituosa, distorcida e polêmica, primeiro do Movimento Futurista, depois, consequentemente, do Modernismo Brasileiro. Uma série de artigos publicados pela redação do jornal oito dias antes da realização da Semana de Arte Moderna, iniciada no dia 03 de fevereiro de 1922, colaborou em grande escala, para que as recepções do evento fossem das mais conturbadas possíveis. A série foi comentada por Jason Tércio (2019) em sua recente biografia sobre Mário de Andrade. $O$ autor traz informações interessantes a respeito da constituição material da série: apresenta alguns elementos acerca do seu suporte de publicação, mas não aprofunda significativamente na análise do conteúdo das discussões, um dos centros de interesse deste estudo. 
A série foi nomeada "A semana futurista" - um tipo de galhofa com o nome do evento. Sua publicação ocorreu entre os dias 03 e 17 de fevereiro de 1922, na seção "Notas de arte". Nos dias 03, 04, 07, 08, 10 e 13 de fevereiro, a série foi publicada em formato de debate, e entre os dias 14 e 17 de fevereiro, o conteúdo dos artigos visavam apenas a crítica aos espetáculos ocorridos durante o evento da Semana de 22.

No que concerne ao formato de debate da primeira parte da série, os artigos eram divididos em duas colunas: uma das colunas era designada como "Pró - Arte moderna", e abrangia o artigo do intelectual que defendia a realização da Semana de Arte Moderna e que afirmava que o evento se tratava da divulgação de uma arte legitimamente moderna e não futurista. A outra coluna, designada como "Contra - Arte futurista", afirmava que a realização da Semana se tratava de uma "Semana futurista", e que a arte defendida pelos intelectuais do movimento era fruto do futurismo brasileiro. Dessa forma, uma mesma nota trazia em seu conteúdo duas espécies de artigo, duas opiniões públicas diversas. Algo que, segundo Jason Tércio (2019), era novidade na imprensa paulistana.

A série teve um grande destaque na primeira página do jornal, mostrando dessa forma, que a discussão em torno do tema em questão se configurava como algo muito importante para a revista. Segue abaixo a imagem do artigo do dia 07 de fevereiro:

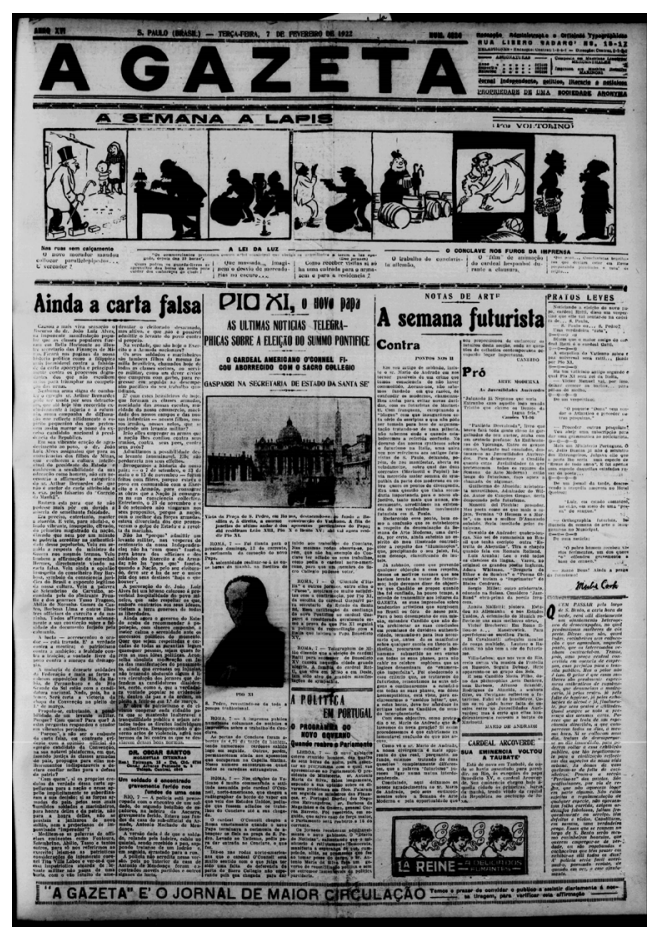

Figura 2 - A Gazeta, 07 de fevereiro de 1922, "A semana futurista", p. 1

Fonte: Hemeroteca Digital Brasileira 
Até o dia 10 de fevereiro, o debate foi realizado entre um colaborador do jornal, sob o pseudônimo "Candido", e um intelectual convidado. Candido, de acordo com Jason Tércio (2019), é provavelmente o historiador, jornalista e escritor brasileiro Benevenuto Sant'Anna -, o qual havia escrito uma série, no mesmo periódico, intitulada "Os Novos - Subsídios para uma reação antifuturista", que tinha como objetivo fazer conhecido os princípios estéticos do Futurismo - no caso, sob a ótica de alguém que desaprovava o movimento. Já o convidado era o escritor e poeta Mário de Andrade, responsável pela defesa da arte moderna e da realização da Semana. Tendo em vista que a imagem do poeta foi fortemente marginalizada pela imprensa, - associada à agitação política e à balbúrdia cultural após a publicação do artigo de Oswald - os principais ataques realizados por seu oponente, diziam respeito à associação do poeta com o Movimento Futurista - fato este que já havia sido desmentido pelo próprio poeta, conforme vimos anteriormente.

Logo na primeira publicação, antes mesmo da exposição das opiniões dos dois articulistas, a redação do periódico expôs uma nota explicando o motivo da realização do debate:

A 'Semana de Arte Moderna', a realizar-se proximamente no theatro Municipal, vem agitando de tal forma o nosso meio artistico e intellectual que conservar-se alheio a esse movimento seria dar provas de um 'parti-pris' que não se coaduna absolutamente com o grau de progresso a que atingiu a imprensa moderna. (A 'SEMANA... 1922)

Dessa forma, verifica-se que a redação do periódico estava mais interessada em seguir o movimento de agitação e polêmica proporcionado na imprensa, do que verdadeiramente construir uma conferência de ideais. No primeiro artigo de Mário, o poeta insistiu em defender o acontecimento da Semana e tentar desfazer, mais uma vez, o mal-entendido criado pela imprensa: "O que vai realizar-se é bem uma Semana de 'Arte Moderna'. Não nos cingimos absolutamente ao futurismo contraditório, embora às vezes admirável, de Marinetti" (Andrade 1922: 1). O conteúdo do trecho citado é uma réplica ao nome escolhido pela redação do jornal para a série de artigos. O título "Semana futurista" não só revelava uma posição contrária à realização do evento, mas também criticava, em tom zombeteiro, todo o movimento surgente.

Nesse artigo, Mário afirmava, ainda, em nome de todo o grupo inovador, a necessidade de serem atuais e de derrubarem antigos valores estabelecidos na sociedade brasileira: valores que advinham de antigas estruturas literárias - o que de certa forma serviu para acirrar ainda mais o debate, visto que a crítica do poeta estava direcionada, mais uma vez, para os aspectos conservadores, tradicionais e enrijecidos da cultura brasileira.

No primeiro artigo, Candido, por sua vez, se concentrou em criticar o Movimento Modernista, tomando-o genérica e novamente por "movimento futurista", além de explicar ao leitor o motivo da pausa na continuidade das suas "syntheses futuristas", a série assinada por Nuto Sant'Anna mencionada acima. A crítica era direcionada a uma suposta troca de "última hora", do nome de "Semana futurista" para "Semana de Arte Moderna" - algo que Mário de Andrade desmentia em seu primeiro artigo. A crítica do debatedor não se dirigia especificamente aos 
ideais do movimento de Marinetti, mas, sobretudo, à apreensão, absorção e transformação destes ideais na nova produção artística brasileira:

A mudança de título de "Semana futurista" em "Semana de Arte Moderna", si de um lado prova a veracidade da affirmação de Papini de que o futurismo transplantado da Italia para outras regiões seria simplesmente ridiculo, mostra também que os 'sois-disant' futuristas de S. Paulo cahiram, mais depressa do que se suppunha, nos braços dos representantes de ideaes estheticos, se é que os têm, totalmente diversos dos seus. (Candido 1922: 1, grifos nossos)

No segundo dia de publicação dos artigos, Mário comparou o discurso de Candido a um "terreno de agua", em que o jornalista edificava os seus escritos, e chamou as considerações do autor acerca do Futurismo de "inuteis illuminações". O poeta manteve uma postura não somente de defesa da arte moderna, mas também, da integridade de sua própria imagem e do movimento que surgia: ele trouxe à tona o conteúdo polêmico do artigo de Oswald, de 1921, explicando que o escrito não deveria mais ser levado em conta, visto que o próprio Oswald, e posteriormente ele mesmo, Mário de Andrade, já haviam esclarecido o tom errôneo e empolgante da afirmação de 1921:

A erronia, é verdade, começou por nós. Oswaldo de Andrade chamou-nos futuristas um dia. Mas o largo sentido em que tomava a palavra foi bastante explicado mais tarde por elle mesmo e luminosamente em seguida, numa chronica de Helios, por Menotti del Picchia. E no 'Jornal do Commercio', de 6 de junho passado, assignei um artigo em que me excluía do futurismo [...] Si Candido insiste em ver na mocidade que dará a 'Semana de Arte Moderna' escravos escandalosos do autor de Mafarka, ou não tem seguido atenção as nossas letras, ou de caso pensado finge desconhece-las. (Andrade 1922)

Depois da publicação dos dois primeiros artigos de Mário, explicando o equívoco cometido por Oswald de Andrade, os conteúdos dos próximos escritos de Candido sofreram uma pequena alteração: os artigos posteriores não se concentrou mais em combater o "futurismo paulista", - visto que Mário já havia desmentido, logo no primeiro artigo da série, qualquer possibilidade de surgimento de um movimento único -, mas Candido se limitou a criticar isoladamente os conceitos estéticos de Marinetti nas variadas artes: na música, nas artes plásticas e na literatura, e não mais atacou diretamente a imagem de Mário, nem dos modernistas principiantes.

A nota anônima publicada pela redação do jornal na seção "Notas de arte" no dia 30 de janeiro de 1922, também intitulada "Semana futurista...", pode ser considerada como a atitude embrionária da série que se iniciou em fevereiro. O posicionamento antagonista do periódico já era evidente logo no primeiro anúncio sobre o festival. Segue abaixo o trecho da notícia, e a imagem da página em que foi publicada: 
Um grupo de distintos cavalheiros da nossa sociedade vai tentar a organização de uma "semana futurista" que será, sem dúvida, o maior escândalo artístico de que se tem notícia em S. Paulo. [...] o Futurismo é, entre nós, a fantasia mais grotesca possível em arte, é a extravagância elevada a impertinentes exageros, e tem provocado a mais sincera reprovação. [...] Nós, que pensamos que a arte deve ser compreendida por todos, esperamos, cheios de curiosidades, a realização desse certame e prometemos, desde já, a nossa crítica severa contra a iniciativa. (A Gazeta 1922: 1)

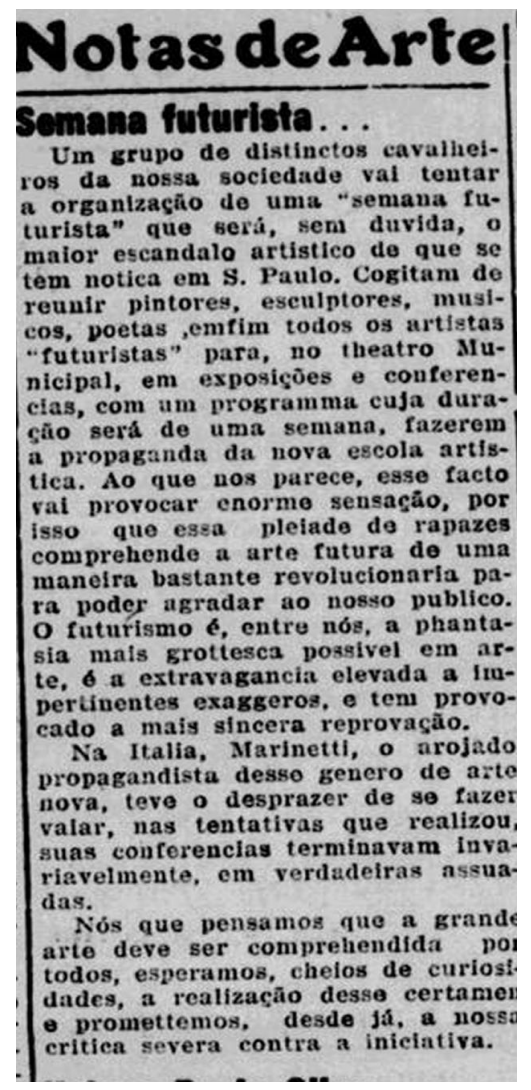

Figura 3 - A Gazeta, 30 de janeiro de 1922, "Semana futurista...", p. 1

Fonte: Hemeroteca Digital Brasileira.

Portanto, deve-se considerar que a redação do jornal não somente se posicionou contra a disseminação de ideias futuristas no contexto artístico e cultural brasileiro, mas também, e sobretudo, contra o próprio movimento modernista - visto que tomaram toda a disseminação das ideias de arte moderna como uma simples reprodução do que dizia o manifesto de Marinetti, conduzindo todo discurso do conteúdo das notícias sobre a Semana a um nível de revolta. O debate de Mário de Andrade e Benevenuto Sant'Anna durou apenas até um dia antes 
da abertura do festival da Semana de 22, momento em que a série passou por uma mudança na materialidade de sua apresentação e começou a expor em um único artigo, as considerações acerca das apresentações ocorridas durante a Semana de Arte Moderna.

A confusão acerca dos termos futurismo e modernismo, contudo, não se encerrou com a finalização da série no dia 17 de fevereiro. Após a fundação da revista Klaxon: Mensário de Arte Moderna, em 15 de maio de 1922 - dois meses após a realização da Semana -, o grupo de intelectuais contribuintes e fundadores da revista: Mário de Andrade, Menotti del Picchia, Graça Aranha, Oswald de Andrade, Manuel Bandeira, Anita Malfatti e Di Cavalcanti, ainda enfrentavam as mesmas duras críticas. Acusados de "futuristas", ainda eram citados desta forma em muitos artigos - em sua grande maioria, de autoria não reconhecida. As acusações eram tão frequentes que na apresentação da primeira edição da revista, Mário fez questão de explicar aos assinantes, mais uma vez, que a revista não se tratava de um "motim futurista": "Klaxon não é futurista. Klaxon é klaxista" (Andrade 1922: 1).

A respeito da série de artigos publicada pela $A$ Gazeta, em 03 de fevereiro, oito dias antes da primeira exposição artística do festival da Semana, é importante considerar que a publicação de um material desta categoria, no qual um intelectual assumia uma posição contrária à realização de um determinado tipo de arte, enquanto outro se apresentava em posição favorável, mostra bem a que profundidade chegaram as discussões a respeito de arte moderna no país à época. Demonstra igualmente, acima de tudo, o importante papel que exerceram os periódicos na articulação dessas opiniões, conduzindo, dessa forma, a sociedade brasileira - no mínimo os leitores diretos e indiretos das polêmicas modernistas nos jornais - a determinada visão do que estava sendo produzido no campo artístico-cultural do país naquele momento.

\section{Os "Futuristas" e a condenação da busca de uma arte original}

Diante de tudo o que foi exposto, deve-se considerar que os intelectuais renovadores buscavam, acima de tudo, uma arte original, desvinculada de antigas concepções europeias. Mesmo tendo como base do movimento a assimilação de muitos conceitos estéticos que circulavam na Europa da primeira metade do século XX, o grupo de romancistas, poetas, pintores, músicos, e escultores brasileiros buscava, antes de tudo, a consolidação de um projeto de nação: o Modernismo Brasileiro foi um movimento nacionalista desde o seu início.

A busca por uma arte original se refletia, na verdade, na busca da edificação de um projeto de emancipação da arte brasileira. Segundo o próprio Mário de Andrade, o Modernismo no Brasil foi um movimento que buscou a independência da literatura brasileira, construindo as suas bases em uma atividade de ruptura que, de acordo com o poeta, era resultado de um "abandono de princípios e de técnicas consequentes [...] uma revolta contra o que era a inteligência nacional" (Andrade 1942: 235). O movimento de reverificação da inteligência nacional, consistia, sobretudo, em revisitar o passado para, adiante disso, constituir as bases de um novo fazer literário.

Essa constante menção ao passado, enquanto procedimento revisionista, entretanto, contribuía de forma mais plena para a agitação das discussões sobre a arte moderna na imprensa brasileira. O inevitável confronto com os valores artístico-literários tradicionais, recebeu da 
sociedade erudita e, posteriormente, do contexto social público, uma resposta que ia além do debate restrito às artes e à literatura: foi levado ao âmbito cultural mais amplo, visto que incluía questionamentos sobre hábitos culturais enraizados naquela sociedade e tencionava trazer à tona aspectos genuinamente nacionais ainda pouco valorizados na cultura nacional.

Apesar das acusações realizadas por parte da imprensa, de que os intelectuais inovadores eram apenas reprodutores de uma arte já realizada em outros lugares, a importação de ideias estrangeiras por parte do grupo modernista não ocorreu de forma inconsciente, mas sim, se considerarmos o pensamento de Jason Tércio (2019), como um processo que garante certo grau de emancipação:

a crítica dos 'antimodernistas' brasileiros à suposta 'imitação' dos modelos europeus denotava uma visão anticosmopolita, fechada para o mundo, sem noção do significado (e da inevitabilidade) da circulação internacional de ideias. Era também decorrência de insegurança diante da influência estrangeira, vista como perigosa ameaça, não como algo natural na História do mundo [...] Uma contradição curiosa dos nacionalistas brasileiros da década de 1920 era que eles aceitavam com naturalidade consumir bens materiais importados da Europa (até porque a indústria local era incipiente), mas não ideias modernas, como se fossem um perigo para a soberania do país, cuja identidade sequer estava completa. (Tércio 2019: 139, grifos nossos)

O Movimento Modernista, dessa forma, foi mal interpretado desde o início de sua difusão pela imprensa: associado errônea e unicamente ao Movimento Futurista, à agitação política, e à má conduta social, o movimento foi tomado como um desvio, uma transgressão das regras de comportamento da sociedade da época, sendo amplamente divulgado e caracterizado como um movimento não somente literário, mas ideológico, cultural e político - o que, inevitavelmente, se tornou de fato. Os embates criados em torno das novas concepções artístico-literárias adquiriram a caracterização de verdadeiros e legítimos combates: o jornal assumiu uma função de "arena" das ideias; a solução para a contenção da ameaça de um possível estouro do Movimento Futurista no Brasil seria a eliminação a toda e qualquer ideia que lembrasse ou se assemelhasse ao movimento.

De acordo com Annateresa Fabris (2011), os "antimodernistas", ao combaterem o Futurismo como "forma excessiva [...] não defendiam apenas um modelo de arte. Defendiam também, e sobretudo, um modelo de sociedade, do qual a arte era a expressão sublimada" (Fabris 2011: 4). Sendo assim, a busca de uma arte nacional, mesmo que completamente nova e divergente do que vinha sendo produzido no país até então, gerou conflitos que foram além do esperado, e não se detiveram somente nos meios acadêmicos e literários.

As diversas concepções estéticas e ideias modernas provenientes das vanguardas europeias, foram transformadas erroneamente em solo brasileiro pelos "antimodernistas", em "ideias futuristas", formadoras de uma verdadeira "frente futurista", ou melhor dizendo, de uma "vanguarda futurista" brasileira e o movimento plural e dinâmico do Modernismo Brasileiro foi reduzido a um suposto "futurismo paulista". Portanto, deve-se considerar que, o conteúdo 
conflituoso das notícias sobre os eventos realizados em torno das novas ideias de arte, e os embates literários expostos no espaço público dominante - o jornal - contribuíram, de forma definitiva, para ampla divulgação e desenvolvimento do Movimento Modernista Brasileiro: de movimento artístico, alvo da discussão pública, transformou-se em movimento ideológico, cultural, social e político. Todavia, as histórias literárias atuais comprovam que o polêmico novo movimento constituiu-se, também, como uma das manifestações mais genuínas da literatura brasileira.

\section{NOTAS}

* Letícia Gonzaga Chacon é licenciada em Letras pela Universidade Federal de Goiás em 2019. Durante a graduação, foi voluntária no Programa de Iniciação à Pesquisa Científica da UFG, onde desenvolveu uma pesquisa sobre a recepção da obra do poeta pernambucano João Cabral de Melo Neto na educação básica pública. Atualmente, é bolsista da CAPES e mestranda no Programa de Pós-Graduação da Universidade Federal de Goiás. Desenvolve na sua pesquisa de mestrado, o estudo da primeira série de crônicas do escritor Machado de Assis, enfatizando, no seu trabalho, a relação que elas estabelecem com o seu contexto de produção e publicação na imprensa brasileira.

** Priscila Renata Gimenez é Doutora em Letras pela UNESP/SJRP e em Literatura Francesa pela Université Paul Valéry Montpellier III (França). Foi bolsista FAPESP, FAPESP/BEPE e beneficiada do Programa de Doutorado com Estágio no Exterior - PDEE/ CAPES. É docente efetiva do Departamento de Línguas Estrangeiras, Área de Francês, da Faculdade de Letras da Universidade Federal de Goiás desde 2016. É docente do Programa de Pós-Graduação em Letras e Linguística da Faculdade de Letras/ UFG e trabalha com linhas de pesquisa sobre Literatura Comparada, Literatura e Imprensa, Imprensa e Tradução, Transferência Cultural e Circulação internacional de impressos.

\footnotetext{
${ }^{1}$ De acordo com Annateresa Fabris (2011), a primeira menção ao Futurismo na imprensa brasileira ocorreu no artigo do escritor português Manoel de Sousa Pinto, que publicou, no periódico mencionado, uma crônica intitulada "O futurismo (À hora do correio)", no dia 06 do mês de abril de 1909. Segundo a autora, o escritor apresentou o manifesto de Marinetti "como uma daquelas provocações que caracterizavam o início do século 'com sua semântica extravagante, acrescida por uma jactância verbosa e arremetedora' " (Fabris 2011: 2).

${ }^{2}$ Trata-se da publicação do poema "Tu", de Paulicéia Desvairada (1922), de Mário de Andrade, lançado na imprensa brasileira em primeira mão através do artigo de Oswald de Andrade intitulado "O meu poeta futurista", publicado em 1921, no Jornal do Commercio (Edição de S. Paulo). A crítica considerou a obra como "futurista" dado o seu caráter inusitado, extravagante e, principalmente, devido tom de manifesto do artigo de Oswald - algo que será explorado por nós até o final deste artigo.

${ }^{3} \mathrm{O}$ termo "passadismo" foi amplamente utilizado pelos intelectuais líderes do Movimento Modernista, no ano de 1921, para a construção da crítica ao tradicionalismo nas artes literárias naquele momento: os intelectuais apresentavam uma postura de combate às formas consagradas da literatura, às rimas fixas e métricas do parnasianismo, às descrições realistas, ao regionalismo e ao sentimento exacerbado do romantismo (Brito 1997).
} 
Cadernos de Literatura Comparada

As 'Vanguardas Futuristas' Brasileiras: o embate literário nos periódicos dos anos 1920

${ }_{4}$ De acordo com Mário da Silva Brito (1997), Oswald de Andrade foi considerado o importador do futurismo no Brasil devido à realização de uma viagem à Europa em 1912 e do seu contato, mais próximo, com a teoria de Marinetti. As considerações mais polêmicas acerca desse suposto futurismo dizem respeito à composição do poema "Último passeio de um tuberculoso pela cidade", também em 1912. Primeiro poema em versos livres da literatura brasileira, de inspiração urbana e descritivo (Brito 1997), foi posteriormente descartado pelo poeta devido às controvérsias que gerou.

${ }^{5}$ Assinalamos na citação a seguir, e também nos demais excertos citados neste artigo, a manutenção da grafia do português da época de publicação. Consideramos dessa forma, a integridade da materialidade das publicações originais, que acreditamos poder contextualizar melhor a leitura dos textos.

${ }^{6}$ Considerando que o artigo de Oswald não se encontra disponível para consulta em sites eletrônicos, extraímos os excertos diretamente de Brito (1997), visto que o autor reproduziu o artigo de Oswald na íntegra em sua obra crítica.

${ }^{7}$ A despeito do caráter democrático da imprensa periódica, o índice de analfabetismo no Brasil ainda era muito alto nesta época. O acesso às notícias e polêmicas dos periódicos, tal como no século XIX, existia de forma mais abrangente, portanto, provável e principalmente por meio da leitura de impressos em bibliotecas, gabinetes de leitura - públicos e privados - saraus e encontros sociais, literários e de leitura, em que muitas vezes se lia em voz alta partes dos periódicos

\section{Bibliografia}

Andrade, Gênese (2013), "Oswald de Andrade em torno de 1922: descompassos entre teoria e expressão estética", Remate de Males, 113-133.

Andrade, Mário de (1942), "O Movimento Modernista", O Estado de S. Paulo.

- - (1921), "Futurista?!", Jornal do Commercio (Edição de São Paulo).

- (1922), "Klaxon", Klaxon: Mensário de Arte Moderna.

- (1922), "A Semana Futurista", A Gazeta (Edição de São Paulo).

Andrade, Oswald (1921), "O meu poeta futurista", Jornal do Commercio (Edição de S. Paulo).

"A 'SEMANA" (1922), A Gazeta (Edição de s. Paulo).

Brito, Mário da Silva (1997), História do modernismo brasileiro. Antecedentes da Semana de Arte Moderna, Rio de Janeiro, Civilização Brasileira.

Candido (1922), "A Semana Futurista”, A Gazeta (Edição de S. Paulo).

Fabris, Annateresa (2011), "O futurismo como estética patológica: alguns aspectos de sua recepção no Brasil", Artelogie, n. 1, 1-8.

Lobato, Monteiro (1917), "A propósito da exposição Malfatti”, O Estado de S. Paulo.

Nunes, Benedito (2002), "Estética e correntes do Modernismo", in O Modernismo, São Paulo, Editora Perspectiva, 39-53. 
"SEMANA futurista" (1922), A Gazeta (Edição de São Paulo).

"O FUTURISMO" (1922), A Gazeta (Edição de S. Paulo).

Tércio, Jason (2019), "O ano da re(vira)volta", in Em busca da alma brasileira - biografia de Mário de Andrade, Rio de Janeiro, Estação Brasil, 117-158.

Thalassa, Angela (2007), "Correio Paulistano: o primeiro diário de São Paulo e a cobertura da Semana de Arte Moderna - O jornal que "não ladra, não cacareja e não morde", São Paulo, Pontifícia Universidade Católica de São Paulo. 